\title{
DEVELOPMENT OF AN INSTITUTIONAL CURRICULUM IN ETHICS AND PUBLIC HEALTH ${ }^{1}$
}

\begin{abstract}
Roberto Cañete ${ }^{2}$, Ada Prior $^{3}$, Katia Brito ${ }^{4}$, Dirce Guilhem5, Maria R. Novaes ${ }^{6}$, Kenneth W. Goodman ${ }^{7}$
Abstract: Bioethics teaching has traditionally focused on classroom activities, but there is a widely recognized need for professional development opportunities for people with active scientific, clinical or administrative duties. Moreover, there is a shortage of evaluations of ethics programs and curricula. In this cross-sectional study, we surveyed hygiene, epidemiology and microbiology professionals who attended 7 ethics courses in Matanzas province, Cuba. The curriculum consisted of 2 main themes: research ethics and public health ethics. The survey comprised pre- and post-test assessments and in-depth interviews of all participants 3 months after the end of each course. Most attendees (i) appeared to demonstrate increased of knowledge in research and public health ethics, including international guidelines, (ii) gave positive assessments of the courses and (iii) affirmed the importance and pertinence of such training activities. This small study is suggestive of the kinds of professional development opportunities available in limited resource settings.
\end{abstract}

Key words: training program, bioethics, public health, postgraduate education

\section{Desarrollo de un plan de estudios institucional en ética y salud pública}

Resumen: La enseñanza de la bioética se ha enfocado tradicionalmente en actividades de aula, pero hay una necesidad ampliamente reconocida de oportunidades de desarrollo profesional para las personas con funciones científicas, clínicas o administrativas activas. Por otra parte, hay una escasez de evaluaciones de los programas de ética y programas de estudio. En este estudio transversal, encuestamos a profesionales de la higiene, epidemiología y microbiología, que asistieron a siete cursos de ética en la provincia de Matanzas, Cuba. El plan de estudios consistió en dos temas principales: ética de la investigación y ética de la salud pública. Esta medición comprendió una pre y post evaluación y entrevistas en profundidad con todos los participantes tres meses después del final de cada curso. La mayoría de los participantes (i) parecía demostrar un aumento de los conocimientos sobre investigación y ética de la salud pública, incluidas las directrices internacionales, (ii) dio una evaluación positiva de los cursos, y (iii) ratificó la importancia y pertinencia de este tipo de actividades de capacitación. Este pequeño estudio sugiere tipos de oportunidades de desarrollo profesional disponibles en entornos de recursos limitados.

Palabras clave: programa de formación, bioética, salud pública, educación de posgrado

\section{Desenvolvimento de um plano de estudos institucional em ética e saúde pública}

Resumo: $\mathrm{O}$ ensino da bioética tem sido enfocado tradicionalmente em atividades de aula, porém há uma necessidade amplamente reconhecida de oportunidades de desenvolvimento profissional para as pessoas com funçóes científicas, clínicas ou administrativas ativas. Por outra parte, há uma escassez de avaliaçóes dos programas de ética e programas de estudo. Neste estudo transversal, pesquisamos profissionais de higiene, epidemiologia e microbiologia, que assistiram a sete cursos de ética na província de Matanzas, Cuba. O plano de estudos consistiu em dois temas principais: ética da investigação e ética da saúde pública. Esta enquete compreendeu uma pre e pós avaliação e entrevistas em profundidade com todos os participantes três meses depois do final de cada curso. A maioria dos participantes (i) parecia demonstrar um aumento dos conhecimentos sobre investigação e ética da saúde pública, incluidas as diretrizes internacionais, (ii) deu uma avaliação positiva dos cursos, e (iii) ratificou a importância e pertinência deste tipo de atividades de capacitaçáo. Este pequeno estudo sugere tipos de oportunidades de desenvolvimento profissional disponíveis em torno de recursos limitados.

Palavras-chave: programa de formação, bioética, saúde pública, educação de pós-graduação

\footnotetext{
${ }^{1}$ Funding: This study was supported in part by a grant from the Centre of Hygiene, Epidemiology and Microbiology. Matanzas City, Cuba. The funders had no role in study design, data collection and analysis, decision to publish, or preparation of the manuscript.

${ }^{2}$ Centre of Hygiene, Epidemiology and Microbiology, Matanzas City, Cuba

${ }^{3}$ Regional Office of the Cuban Ministry of Health, Matanzas City, Cuba

${ }^{4}$ Samuel Fernández Policlinics, Matanzas City, Cuba

${ }^{5}$ Faculty of Health Sciences, Laboratory of Bioethics and Ethics in Research, University of Brasilia, Brasilia, Brazil

${ }^{6}$ School of Medicine, Institute of Health Science- ESCS, University of Brasilia, Brazil

${ }^{7}$ University of Miami, Bioethics Program, WHO Collaborating Center in Ethics and Global Health Policy, Florida, United States of America Correspondencia: kgoodman@med.miami.edu
} 


\section{Background}

A growing concern among those who recognize that healthcare resources are finite has promoted policies of cost reduction and in deep analysis of what is fair and equitable in health service(1). On this contest continuing medical education on ethics has become common in developed and developing countries(2).

There are a number of existing programmes which provide training about research methods for young professionals. Most of them are running throughout new or well-established methodologies and are good enough to be effective; however, ethics and social sciences should be part of those curricula too. Courses in the history of medicine, bioethics, communication, medicine and art, and spirituality and medicine will train physicians who will temper technological medicine with a humanistic touch(3).

Widely recognized, scientific research enhances the effectiveness and efficacy of health systems(4). Considering the past, looking for the present and thinking in the future we could justify that announcement taking into account some general considerations: first, scientific results (positives or not) contribute to optimize processes and to reduce costs and second, when facing critical situations the evidences provided by investigators can determine in the permanency, modification or even elimination of certain programs or daily practices $(4,5)$.

The Centre of Hygiene, Epidemiology and Microbiology is a second level institution in the $\mathrm{Cu}$ ban Ministry of Public Health created on the second half of the twenty century with a vast history of goals on its mission and a well gained prestige national and internationally so the authorities agree with national standards are now involve in an intensive program to become more effective, reducing costs and increasing scientific production.

The aim of this study was to evaluate the results of the institutional program on research ethics and public health. The programme, still in progress, takes into consideration the principle of learning by doing and complements other continuing medical education programs carried out by different institutions or branch from the Cuban Ministry of Public Health at regional level.

\section{Methods}

\section{Needs Assessment}

To define the necessity for the implementation of a continuing educational programme about ethics and public health, from January to June 2009, an empirical research was carried out to determine the existing practice patterns related with the teaching-learning process of bioethics and the ethical review of research protocols carried out at the Centre of Hygiene, Epidemiology and Microbiology (an administrative, executive and academic institution) and its institutions affiliated from Matanzas, Cuba. Data were collected by documental analysis and interviews.

This research was a mandatory of the director of the centre by suggestion of the president of the Institutional Review Board (IRB). The full report (available in Spanish) of the problems identified and the recommended actions suggested is available under request in the directors' office of the centre. A copy of this document is also available in the IRB records under the code Cód. 2009- 00.

\section{The study}

A cross-sectional study was carried out from June 2009 to December 2012 to evaluate the results of 7 training courses included on the continuing medical education programme in ethics and public health addressed to 120 professionals of the area of Hygiene, Epidemiology and Microbiology in Matanzas-Cuba. All courses (one week each) and the activities associated were accredited by the University of Medical Sciences, MatanzasCuba and could be consulted in the library of that institution under official request.

The curriculum consisted of 2 main themes: "research ethics" and "ethics and public health". Pretest and post-test results of each course as well as the answers to the in-depth interview applied to all participants 3 months after the course end were evaluated. Opinions from 4 professors directly involved on the process were analyzed too. 
The score of each test was assigned from 1 to 10 distributed as: low score (1 to 6), medium score (7 to 8 ), and high score (9 to10) as convenience by researchers.

The institutional curriculum was developed by the IRB members in coordination with the Faculty of Health Sciences, University of Brasilia- Laboratory of Bioethics and Ethics in Research, The School of Medicine, the Institute of Health Science- ESCS, Brasilia- Brazil, and receives materials and suggestions from the University of Miami Bioethics Program. Miss Evers' Boys and Something the Lord Made movies were discussed in all curses to strength and illustrate the information given to the participants.

\section{Data Collection}

At the beginning and 3 months after the end of the courses an in-depth interview was carried out by the main researcher to each participant seeking for: 1. general data like gender, academic degree, previous training on ethics, and education level; 2. five questions regarding knowledge; and 3. five questions regarding practice. In addition, at the end of the activities all trainees had the opportunity to give suggestions and furnish any additional information.

\section{Data Management and Statistical Analysis}

Data derived from interviews, pre and post-test were analyzed using EpiInfo 6.0 software (Public Health Domain Software, CDC, Atlanta, GA, USA). Initial data entry was cross-checked by two independent individuals in order to be sure that information was entered correctly. For descriptive data, rate (percentage) was used to describe the characteristics of the studied group. A Pearson's Chi-square $(X 2)$ on proportion was used to test the associations between each variable. A significant level of $\mathrm{p}<0.05$ was adopted, Relative Risk (RR) and 95\% confidence interval was computed by the analysis.

\section{Ethical Considerations}

Ethical clearance was granted by our Institutional Scientific Council as well as an independent group of advisors selected by the director of the institu- tion from different departments considering that the IRB was involved on the study. The enrollment also required that the agreement model (a component of the informed consent process of this study) were signed by all participants, after being fully informed about the aim of the study.

\section{Important remark}

Health in Cuba is ruled by fundamental basic principles such as the state and social character of medicine, access and universality as well as the implementation of the latest scientific and technological advances according to the conditions of a low-income country.

The Cuban National Health System is highly structured, prevention-oriented and gives special attention to continuing medical education so the results on this area is reflect of an intensive and humanitarian work around the county.

There are some important conditions to take into account in Cuba: 1. our National Health System is homogeneous, deeply organized and integrated; and 2. personnel working for the Cuban National Health System is stable so it is common to find professionals with experience of more than 20, 30 or even more than 40 years keeping their original place of working. This 2 conditions allowed us to easily be in touch with all participants of the courses. Even more, all participants belongs to different dependencies of the area of Hygiene, Epidemiology and Microbiology at regional level so continuing communication is a condition to our daily activities.

All individuals who attended the training courses accept by consent to fill out the pre-test and posttest evaluation as well as the in-depth questionnaire 3 months later because they are fully informed by their duties about the necessity to evaluate all activities to improve them saving additionally the limited available resources and time.

\section{Results}

The initial evaluation to determine the need of a continuing educational programme of research ethics and public health at the Centre of $\mathrm{Hy}$ giene, Epidemiology and Microbiology and its 
institution affiliated from all over the province evidenced at least 2 elements to justify its implementation. First; research activities were only advisory by institutional groups strongly trained in research methodology but less prepared on ethics and second, there were a generalized opinion about the limited experience on bioethics and the need of a continuing educational programme. The full report of the evaluation was discussed with the director of the centre in June 2009 and is available in Spanish under official request.

All individuals who attended the training courses completed the pre-test and post-test evaluation; the in-depth questionnaire applied by the main researcher and approved the training requirements. The 120 trainees came from multi-disciplinary backgrounds including medicine, nursing, administration, social science, dentistry and laboratory science (Table 1$)$. Their ages ranged from 24 to 59 years (29 years old as average) and there were more females $97(80.8 \%)$ than males $23(19.2 \%)$. Ten trainees (8.3\%) were members of the IRB and $32.5 \%$ of all participants reported that they had previous training on ethics.

Table 1. Demographic profile of trainees $(n=120)$

\begin{tabular}{|l|r|r|}
\hline Affiliation of participants & $\mathrm{n}$. & $\%$ \\
\hline Microbiology & 49 & 40.8 \\
\hline Hygiene and Epidemiology & 32 & 26.7 \\
\hline Dentistry & 10 & 8.3 \\
\hline Social sciences & 9 & 7.5 \\
\hline General Medicine & 7 & 5.8 \\
\hline Nursery & 5 & 4.2 \\
\hline Administration & 5 & 4.2 \\
\hline Community & 3 & 2.5 \\
\hline \multicolumn{3}{|c|}{} \\
\hline Qualification * & $\mathrm{n}$. & $\%$ \\
\hline Diplomas on different specialities & 115 & 95.8 \\
\hline First Degree Specialist & 42 & 35 \\
\hline Second Degree Specialist & 7 & 5.8 \\
\hline Master in Sciences & 19 & 15.8 \\
\hline
\end{tabular}

* Participants could have more than one certification.

First and Second Degree Specialist is a classification to differentiate expertise in a specific specialization field in Cuba. Second Degree specialist is the higher level.

83 out of 120 participants (69.2\%) get the high- est evaluation in post-test while $37(30.8 \%)$ were evaluated in medium score. Pre-test were only approved by $39(32.5 \%)$ participants, all of them with previous training on ethics. The difference of pre-test approvals and post-test high score was statistically significant $[R R=0.46$; $C I(0.34$ 0.61)]. $90(75 \%)$ participants answered correctly the in-depth interview 3 months after course finalization and none of them fail this evaluation similar to those receiving the highest score at the end of each courses [RR=0.81; CI (0.54-1.22)]. The results presented are an average of the 2 learning modules (Tables 2 and 3).

Table 2. Pre-test and post-test results from all courses $(n=7)$.

\begin{tabular}{|c|c|c|c|}
\hline $\begin{array}{l}\text { Partici- } \\
\text { pants }\end{array}$ & $\begin{array}{l}\text { Pre-test ap- } \\
\text { provals } \\
\text { Knowledge/ } \\
\text { Skill } \\
\text { n. } \quad \%\end{array}$ & $\begin{array}{l}\text { Post-test } \\
\text { high score } \\
\text { Knowledge/ } \\
\text { Skill } \\
\text { n. } \\
\%\end{array}$ & $\begin{array}{l}\text { RR (CI } \\
95 \%)\end{array}$ \\
\hline 120 & $39 \quad 32.5$ & $\begin{array}{l}83 \\
69.2\end{array}$ & $\begin{array}{l}0.46(0.34- \\
0.61)\end{array}$ \\
\hline
\end{tabular}

Note. $\mathrm{RR}=$ Relative risk; $\mathrm{CI}=$ Confidence interval.

Table 3. Post-test and in-depth interview results from all courses $(n=7)$.

\begin{tabular}{|c|c|c|c|}
\hline $\begin{array}{l}\text { Partici- } \\
\text { pants }\end{array}$ & $\begin{array}{l}\text { Post-test } \\
\text { high score } \\
\text { Knowledge/ } \\
\text { Skill } \\
\\
\text { n. } \%\end{array}$ & $\begin{array}{l}\text { In-depth } \\
\text { interview } \\
\text { high score } \\
\text { Knowledge/ } \\
\text { Skill } \\
\text { n. \% }\end{array}$ & $\begin{array}{l}\mathrm{RR}(\mathrm{CI} \\
95 \%)\end{array}$ \\
\hline 120 & $\begin{array}{l}83 \\
69.2\end{array}$ & $90 \quad 75$ & $\begin{array}{l}0.81(0.54- \\
1.22)\end{array}$ \\
\hline
\end{tabular}

Note. $\mathrm{RR}=$ Relative risk; $\mathrm{CI}=$ Confidence interval.

All participants turn positively their attitudes related with the importance and pertinence of this training activities and the positive contribution for to be better workers instead of 38 (31.7\%) at the beginning of the program. Similar, professors directly involved on the process declared their improvement as professionals as result of the continuing study for each module and its regular updating. Courses attendance was excellent, 98\% 
of activities were carried out with $100 \%$ of trainees inscribed.

Both, trainees and trainers, suggested that would be better in the future to increase the use of the web page of the centre to facilitate all process. Yet, the training is based on classroom activities because of the limitation of most trainees to have access to the web or electronic devices. Only case studies, notification of dates for discussion or material distribution was made using the web or the electronic mail. Face to face discussion using the web is not possible in our centre.

The web page of the IRB, created to support this programme, is already functioning but accessible only from the base institution because of technological limitations. The accessibility to the web page of the IRB was a repetitive request by trainees and trainers still without response by IRB or the administration.

The library of the Centre of Hygiene, Epidemiology and Microbiology in Matanzas, Cuba was the place where most educational activities took place. Administration of this place guaranteed all materials and equipment as well as the participants' requirements during the training period.

\section{Discussion}

The inclusion of the humanities in medical education may offer significant potential benefits to individual professionals and to the medical community as a whole. Debate remains, however, about the definition and precise role of the humanities in medical education, whether at the premedical, medical school, or postgraduate level. Recent trends have revealed an increasing presence of the humanities in medical training(6).

The first step in organizing our training programme was to decide on the intended participants. Considering international tendencies two options were evaluated by the IRB: a. to have a programme designed solely for professionals with previous information about bioethics, such a programme could focus on general ethical principles, the roles and responsibilities and the process of protocol review, and b. to expand the audience to include other stakeholders like accredited re- searchers, administrators, community representatives, and even medical doctors taking part of different specialization programs in this case Microbiology and Hygiene and Epidemiology (one of the main target action of education in our area). After a deep discussion among IRB president and the authorities of the centre the second alternative was considered.

The 7 courses were carried out using the principle of learning by doing combining case studies and protocols evaluation with lectures, movies, working in small groups and the use of electronic mail and the web page. The web page was only accessed if trainees were on the main institution of the area because it is not accessible out of this site. Permanent education is a personal mandatory in Cuba for all health workers so the possibility to learn some novel themes was a challenging action for trainees and trainers.

Cuba has a different model in medical care tightly organized, and the first priority is prevention(7). Even with limited economic resources our health care system has solved some problems that other developed or developing countries have not yet managed to address. This comment is supported by a deep integration of all public health system, decision maker, and society (8).

As was previously mentioned the Centre of $\mathrm{Hy}$ giene, Epidemiology and Microbiology and its institution affiliated from all over the province have a key role in all activities related with public health so the training in research ethics and ethics and public health was necessary in order to keep the highest standards of quality. This comment was supported by the results of the research to determine the necessity for the implementation of a continuing educational programme carried out from January to June 2009 by the main institution of the area.

One specific problem on this kind of activities is the attendance $(9,10)$. Because of daily activities it is very difficult for professionals to take part of any post-graduate training instead they receive a specific authorization from their superiors. Of course, this authorization is far when work load is stressful. All participant of this courses received full time permission to attend so the personnel 
did not miss any programmed activity. This probably plays a pivotal role on final results and the enthusiastic participation on the different activities.

As was expected the trainees came from a multidisciplinary environment, had different level of qualification and were relatively young (29 years old as average). This is a result of the wide range of duties of the area and the expansion experimented during the last 10 years in terms of responsibilities assigned by the regional office of the Cuban Ministry of Public Health and the incorporation of new certified professionals for programs previously inexistent.

It has long been known that an increase in knowledge alone is rarely sufficient to induce real change in personal behaviors. In this particular case we agree with Reed and colleagues(11) about the necessity of developing a Personal Learning Plan as a strategy to promote those desirable behavioral changes. In fact, 80 of 120 professionals who took part of the program are now certified as professors, 25 gets their certification as master and all are involved in research and other continuing educational activities of our province.

Most participants get the highest evaluation and all approved the post-test. This is real impressive considering that only 39 of 120 approved with medium score the similar pre-test. The possible answer to this situation is the interest by a topic not fully understood at the beginning but widely recognized as one of the contributors to become better workers at the end.

The in-depth interview applied to all participants 3 months after course finalization to determine if they translated the information received into knowledge to carry out their daily activities demonstrated that most of them get the highest evaluation. We may consider here the integration of the program goals with the institutional and regional objective for development for the period 2012- 2015.

Another important aspect of the courses was the discussion among all trainers and trainees of almost all national and international guidelines and regulations on research ethics and public health.
Electronics copies of these guidelines and regulations were provided to all trainees as well as papers, books, movies and recorded interviews with experts on Bioethics.

The desirable change was possible by the integration of all educational activities carried out by the IRB using all regular meetings to discuss cases, critically evaluate lectures presented in scientific meetings, reading papers recently published, and suggesting movies with special emphasis on good human behavioural and practice. It is important to remark the great impact of the discussion of Miss Evers' Boys movie both in the courses and with specific meetings with all personnel of the different institutions. In our opinion this film could effectively illustrated the bad practices in science only limited to Nazis' experiments for a great number of professionals not well illustrated on bioethics.

Our reality, probably similar to those presented in other developing countries, does not allow us to use extensively the web. Cuba, as low income country, has no strong enough infrastructure to cover this alternative. This fact does not avoid reaching our goal.

The development and implementation of this curriculum provided a variety of important lessons, most of them desirables. First, the incorporation and utilization of existing human resources with excellent background on this field; second, the need of integration with existing objective for development in health at national and regional level; and third, the pivotal role of existing and well established international centres who support this educational activities not only with electronic documents but also participating in curricula designing, advising on how to provide information to trainees and, of course, facilitating the train to trainer activities.

Our curriculum enhances knowledge acquisition, skills development and the perception of ethical values in the context of professional conduct.

\section{Conclusion}

As result of the development and implementation of our institutional curriculum in ethics and 
public health 120 professionals grew up in their humanistic working mode and were actively incorporated in teaching and research process. All institutions create their Medical Ethics Commission and the IRB of the area was strengthened. This curriculum guaranteed the visualization of the IRB at provincial level so we serve now as advisors for protocols review and teaching activities on research ethics and ethics and public health for the University of Medical Sciences and for the provincial Medical Ethics Commission.

\section{Acknowledgements}

The train to trainer activities were possible by a grant from WHO/TDR- Leadership Development Fellowship Programme (Post-Doctoral training) in 2010 and was executed at the Faculty of Health Sciences, University of Brasilia- Laboratory of Bioethics and Ethics in Research and the School of Medicine, Institute of Health Science- ESCS, Brasilia- DF, Brazil. Special thanks to Dr. Pascal Launois, Dr. Christine Maure, and Najoua Kachouri Aboudi (WHO officials) for their special contribution and professionalism.

References

1. Espinoza Santander I. Bioética y asignación de recursos para la atención odontológica del adulto mayor en Chile. Rev Clin Periodoncia Implantol Rehabil 2011; 4(2): 80-82.

2. Rodriguez E. Learning qualitative aspects of the ethics of biomedical and psychosocial research program of the Interdisciplinary Center for Studies on Bioethics, University of Chile. Acta Bioethica 2012; 18(1): 57-62.

3. Bryan CS, Longo LD. Perspective: teaching and mentoring the history of medicine: an oslerian perspective. Acad Med 2013; 88(1): 97-101.

4. Guilhem D, Neves da Silva L, Cañete R. Responsibilities in research: the roles of sponsors. Türk Hijyen ve Deneysel Biyoloji Dergisi 2010; 67(4): 189-197.

5. Pringle B, Colpe LJ, Heinssen RK, Schoenbaum M, Sherrill JT, Claassen CA, et al. A strategic approach for prioritizing research and action to prevent suicide. Psychiatr Serv 2013; 64(1): 71-75.

6. Wershof Schwartz A, Abramson JS, Wojnowich I, Accordino R, Ronan EJ, Rifkin MR. Evaluating the impact of the humanities in medical education. Mt Sinai J Med 2009; 76(4): 372-380.

7. Campion EW, Morrissey S. A different model-medical care in Cuba. N Engl J Med 2013; 368(4): 297-299.

8. Domínguez-Alonso E, Zacca E. Sistema de salud de Cuba. Salud Pública Mex 2011; 53 (supl 2): S168-S176.

9. Burnand H, Mutimer J. Surgical training in your hands: organising a skills course. Clin Teach 2012: 9(6): 408-412.

10. Montero L, Triviño X, Sirhan M, Moore P, Leiva L. Barriers for faculty development in medical education: a qualitative study. Rev Med Chil 2012; 140(6): 695-702.

11. Reed VA, Schifferdecker KE, Turco MG. Motivating learning and assessing outcomes in continuing medical education using a personal learning plan. J Contin Educ Health Prof 2012; 32(4): 287-294.

Received: August 12, 2013

Accepted: October 13, 2013 